\title{
INTELLIGIBILITY AND THE GUISE OF THE GOOD
}

\author{
Paul Boswell
}

1 AVE CLAIMS he had never before considered suicide, and he does not recall being depressed or even sad at the time. But late one otherwise-ordinary night, while walking down a quiet street, Dave saw a car approaching, and it occurred to him that_as he later put it_- "what I should do would be to kneel in the street and be hit by the car. It seemed to make perfect sense to me. And so that's what I did." The car screeched to a halt just in front of him, and a man got out and demanded to know what he was doing. According to Dave, "I looked at him, and I said, 'I don't know.' I had no idea. I had no explanation for him.... I still today — what, 25 years later — don't understand what that was and why I did that."

In spite of the fact that in some way it made sense to him to kneel down, in another way it must have been utterly unintelligible to Dave to kneel. After all, he could find no reason for his action. Cases like Dave's thus motivate what is often called the Intelligibility Constraint (IC) on action for a reason:

IC: If an agent $\phi$ s for a reason, then $\phi$ ing is intelligible to her (according to a certain sense of "intelligible").

IC is not exactly a platitude, concerning as it does an intuitive yet unarticulated notion of intelligibility (about which more later). Moreover, it depends upon a particular notion of action for a reason that entails having a genuine reason of one's own for acting. If instead, after months of psychotherapy, Dave were to unearth a repressed fear of appearing to be a failure to his father, and to discover that his genuflection so many years ago was a kind of prayer for forgiveness, then there would be another sense in which he knelt for a reason: he did it in the hope that he would be forgiven. (Call this case "Freudian Dave.") But so long as we stipulate that at the time of action this motivation was fully repressed and that Freudian Dave had absolutely no idea why he was kneeling, then such a motiva-

1 Glass, "Devil on My Shoulder."

2 Glass, "Devil on My Shoulder." 
tion does not speak to a reason of his for kneeling. To be a bit more explicit, I can grant that Freudian Dave has motivating reasons for action in his unconscious beliefs and drives. The sense in which he does not have a reason for action, however, is Anscombian: it is because there is no positive answer to the "Why [did you do that]?" question, at least as addressed to him. ${ }^{3}$ This latter, full-blooded sense of reasons for acting is the sense I am concerned with here.

IC, then, claims that there is a deep connection between this full-blooded sense of acting for a reason and a certain way in which actions may or may not be intelligible to their agents.

One traditional and perennially popular theory in the philosophy of action, the Guise of the Good (GG), is often held by its proponents to explain IC. ${ }^{4}$ According to GG, an action done for a reason must be seen as good by its agent, for a certain sense of "seen as good." Furthermore, it holds that action for a reason must be intelligible to its agent because for an action to be intelligible in the relevant way just is for it to be seen as good, in that sense of "seen as good." Now, it so happens that current GG theories can be divided almost neatly into two camps according to how they think of such appearances of the good. Attitudinal views hold that these appearances have a presenting-as-good character but that normative notions need not figure in the content of these states. Assertoric views hold that these appearances are better understood as representations with normative content that are presented with assertoric rational significance-that is, the rational significance possessed by belief and perception that consists in their power to defeasibly license further beliefs and inferences from that content. ${ }^{6}$

In this article, I present a dilemma for the attitudinal theorist who aims to ex-

3 Anscombe, Intention, 9.

4 See Anscombe, Intention; Quinn, "Putting Rationality in Its Place"; Raz, "Agency, Reason, and the Good" and "On the Guise of the Good"; Tenenbaum, Appearances of the Good; Sussman, "For Badness' Sake"; Johnston, "The Authority of Affect," 189-90; Schapiro, "The Nature of Inclination," 251-53; and Boyle and Lavin, "Goodness and Desire," 188-89, among others. Note that Johnston and (sometimes) Anscombe focus more on how a certain relation to evaluation can make desiring, as opposed to acting, intelligible. Especially in the case of Johnston, this leaves to some extent open the question of whether they accept the precise form of GG I am interested in here, one that concentrates on action for a reason. I leave this exegetical point aside in the rest of the article, however. For a concern about whether Quinn accepts IC, see note 32 below.

5 See Anscombe, Intention, 70-78; Tenenbaum, Appearances of the Good, 32-33; Wiland, Reasons, 49-52.

6 Schroeder ("How Does the Good Appear to Us?"), Schafer ("Perception and the Rational Force of Desire"), and Baker ("The Abductive Case for Humeanism over Quasi-Perceptual Theories of Desire," 4-5) refer to similar distinctions between kinds of GG theories. The term "assertoric" was introduced to the debate by Schafer ("Perception and the Rational 
plain IC. The dilemma arises out of an objection from Kieran Setiya, who argues that merely seeing an action as good does not suffice to render that action intelligible. ${ }^{7}$ (Indeed, as we will see, Dave's case is good evidence that he is right.) If that is so, it imperils GG's explanation of IC. I show that the very feature that GG theories need in order to answer this objection-the feature of motivation's presenting a specific form of the good—forces them to characterize their view in a way that either favors the assertoric model or fails to capture the intelligibility of action. The crux of the argument is that attitudinal views are fundamentally unable to account for agents' mental access to the good.

The immediate upshot of the article is that GG theorists should move to assertoric formulations of the view, at least insofar as they rely on the intelligibility motivation. But in another way, the impact of the argument is broader. Near the end of the article, the dilemma I present gives way to a general argument that attitudinalist accounts of the intelligibility of action, whether they are GG views or not, fail precisely because action is intelligible to an agent in virtue of the content of the agent's mental states.

A subsidiary aim of this article is to articulate an account of the intelligibility motivation for GG, a motivation frequently referenced in the literature but rarely set out at length. I give a limited defense of it here, focusing exclusively on defending it from Setiya's objection. This I do in section 2 after introducing GG more thoroughly in section 1 . Section 3 then presents the dilemma against attitudinal views.

\section{THE GUISE OF THE GOOD}

GG is really a family of views that all hold that human action or motivation to act, of some special kind or another, is only possible insofar as the agent acts or is motivated to act because of the good she sees in so acting. ${ }^{8}$ According to these views, goodness, or apparent goodness, plays a primary role in the motivation and rationalization of action. ${ }^{9}$ Before setting out the attitudinal and assertoric versions of the view, I flag four key features of the GG family.

GG has been held by various authors to be a constraint on action for a rea-

Force of Desire"), though he uses it to qualify a kind of Fregean force that he holds explains the rational significance of perception and belief.

7 Setiya, "Sympathy for the Devil." Derek Baker (“The Abductive Case for Humeanism over Quasi-Perceptual Theories of Desire") has also pressed a version of this objection.

8 See Tenenbaum, "Guise of the Good," and Orsi, “The Guise of the Good," for recent overviews.

9 See for instance Raz, "Reasons," on what he calls the "normative/explanatory nexus." 
son, intention, intentional action, will, or, chiefly, desire. ${ }^{10}$ Because my concern is with GG theories generally, and because it is reasonable to assume that GG constrains action for a reason if it constrains intentional action or desire, here I investigate the weakest form of the view, one holding only that action for a reason must appear good to its agent.

There is a related dispute over the nature of the appearance of the good that the view requires. Many authors hold that desires are appearances of the good or that they involve or express thoughts about or perceptions of the good, but others hold that these required appearances are distinct from desires, such as motivating beliefs about the good. ${ }^{11}$ I am skeptical that desires are appearances of the good, but the argument in this paper does not require me to take a side on this issue. My focus is on the form and content of these allegedly required, motivating appearances of the good, whatever they may be. For that reason I speak generically of motivation as an appearance of the good. GG theorists can substitute for "motivation" their favored appearance-state, be it desire, evaluative belief, etc.

GG requires more than that when agents act for a reason they see that act as good. It further requires that they act because of the (apparent) good, or that they are guided by the good. ${ }^{12}$ Similarly, GG requires more than that action for a reason is guided by the good in some way or another, for it entails that agents who act for a reason are guided by their mental access to the good. This point differentiates GG from constitutivism, which attributes necessary aims or standards to agency but which is not generally committed to epistemic claims about agents' access to those standards. ${ }^{13}$ An implication of this same point is that GG is not

10 As a constraint on action for a reason, see Raz, "Agency, Reason, and the Good," 22-23. As a constraint on intentional action, intention, or will, see Aquinas, Summa Theologiae, I-II 1.1, 94.2; Davidson, "How Is Weakness of the Will Possible?" 22; Raz, "Agency, Reason, and the Good"; Buss, "What Practical Reasoning Must Be If We Act for Our Own Reasons," 400; Anscombe Intention, 75. As a constraint on desire, see Stampe, "The Authority of Desire"; Oddie, Value, Reality, and Desire; Tenenbaum, Appearances of the Good; and many others.

11 Tenenbaum, Appearances of the Good; Quinn, "Putting Rationality in Its Place," 36; Scanlon, What We Owe to Each Other, 37-41; Buss, "What Practical Reasoning Must Be If We Act for Our Own Reasons"; Gregory, "The Guise of Reasons."

This "because" in the formulation of GG is intimately connected with that of reason-explanations of actions, but it should not be construed as entailing that, when an agent $\phi$ s for a reason, her reason for $\phi$ ing is that $\phi i n g$ is good, as such. This would otherwise tend to beg the question against attitudinal views. For there is independent pressure to think that an agent's (nonpsychological) reasons for acting are all to be found among the contents of her beliefs, and as we will see below, attitudinalists believe that the good need not figure in the content of an agent's mental states.

13 Paradigm constitutivists include Velleman, “The Possibility of Practical Reason”; Korsgaard, 
equivalent to the claim that agents, in acting for a reason, are guided by a formal aim of acting or practical reasoning, even when conjoined with the claim that the good is that formal aim. ${ }^{14}$ Indeed, it is possible for an agent to be guided by something of which they have no intimation, as when unnoticed environmental cues affect an agent's choice. ${ }^{15}$ We can also easily imagine a constitutivist theory that holds that agents are guided by the good but not in virtue of their access to it: suppose it is a conceptual truth that agents are guided by certain dispositions, say, to realize their final desires and to know the world in which they live. These dispositions fix an intrinsic standard for agency, so that a perfect agent is one who exercises these dispositions perfectly. The theory could furthermore hold that states of affairs are good relative to an agent just in case, and because, that agent's perfect counterpart desires them. ${ }^{16}$ On this theory, it falls out of the concept of agency that agents are guided by what is good relative to them. However, this is not because of any epistemic access that agents may have to what is good relative to them, but merely because agents are guided by dispositions the perfect exercise of which makes something good relative to them. They are guided by the good but in a "blind" way, as a dynamical system is guided by an attractor. ${ }^{17}$

So let me reemphasize that GG is a double requirement: the agent who acts for a reason must be (a) guided by the good, and (b) so guided in virtue of her access to it. According to GG, the appearance of goodness is crucial to the generation of action for a reason. And were the agent to have no access to what guides them, the guidance would be blind, and not the agent's rational guidance, as action for a reason must manifest. ${ }^{18}$

Self-Constitution; and Smith, "A Constitutivist Theory of Reasons." Note that Velleman rejects GG while holding that agents are necessarily guided by representations of what de re justifies action, though they need not conceive them under that guise. See Velleman, "Introduction," 28n34. Silverstein, "Agency and Normative Self-Governance," gives an exceptionally lucid presentation of Velleman's view on this issue.

Contra Saemi, "Aiming at the Good."

15

The most well-known evidence of this is found in Nisbett and Wilson, "Telling More Than We Can Know."

The toy theory here is inspired by, but distinct from, the constitutivist theory in Smith, "A Constitutivist Theory of Reasons."

17 Some may take issue with describing such agents as guided by the good. Is it not more accurate to say that they are guided toward what is good by their dispositions? But the crucial point, I think, is that given the theory we could explain such an agent's action (say, an attempt to realize a final desire) by saying that they did it because it was good. This noncausal explanation already gives a deflationary sense in which an agent is guided by the good.

18 See Schapiro, "What Are Theories of Desire Theories Of?" $132-33$, for an excellent articulation of this point. 
Lastly, "good" here must not be presumed to refer to value, much less to good-for or to moral, public, or agent-neutral value; indeed, "Guise of Normative Force" or "Guise of Justificatory Force" would be more apt titles for the thesis, if less catchy. The GG family thus embraces "Guise of Ought" and "Guise of Reasons" theorists too. ${ }^{19}$

\subsection{The Attitudinal Model}

The attitudinal model is a long-popular way of understanding appearances of the good. Typically it is applied to desire as the motivation of choice. The point of departure for the attitudinal model is a supposed analogy between belief and truth on the one hand, and desire and the good on the other. The formal object of belief is truth, it is held, and furthermore to believe is necessarily to regard the propositional content of one's belief as true. But truth cannot plausibly be held to necessarily be part of the propositional content of belief, as if regarding one's belief as true were like regarding a project to be a success, since that would set off a problematic regress. ${ }^{20}$ So, truth must relate to some aspect of belief apart from its content. Truth may, for instance, be held to figure in the intentional mode of the attitude of belief- that is, in the manner in which belief represents its propositional content: to believe that $P$ is to represent-as-true that $P$.

According to the attitudinal model of GG, appearances of the good have the same relationship, at least in broad outline, with respect to the good. After all, when one is motivated to bring about that $P$, one is not motivated to bring about that it be good that $P$, but simply that $P$. From this it would appear that goodness need not be part of the content of motivation. So on the attitudinal model, motivation is held instead to be a primitive presenting-as-good attitude, or goodness is considered part of the form of motivation, or it is suggested that it is constitutive of a motivation to bring about that $P$ that it aims to get it right as to whether $P$ is good. ${ }^{21}$

\subsection{The Assertoric Model}

On the assertoric model of GG, an appearance of the good possesses goodness-including content that it presents with the rational significance of belief or Norms"; Gregory, "The Guise of Reasons." 
perception. ${ }^{22}$ Two cognitive, and in a broad sense of the term, representational states can share content and yet differ with respect to rational significance. One's merely imagining that John Rawls is standing in the doorway would not even defeasibly rationalize the belief that John Rawls is standing in the doorway. However, a perceptual experience with the same content would. Thus perception and belief, but not imagination, share rational significance insofar as they both have the power to defeasibly license belief or inference. The thought is then that the motivations at the center of GG are to be understood in terms of beliefs or perceptions concerning good actions.

In the assertoric camp belong Raz, Buss, and Gregory, who all hold that action for a reason requires a belief about the good or about one's normative reasons. ${ }^{23}$ Davidson holds that desires express evaluative judgments. ${ }^{24}$ Oddie and Hawkins take desires to be perception-like experiences of the good. ${ }^{25}$

The assertoric model is frequently rejected as over-intellectual, as it is alleged that it requires animals and small children, who clearly have desires and who arguably can act for reasons, to possess evaluative concepts and exercise them whenever they act for a reason. ${ }^{26} \mathrm{I}$ am optimistic that the problem is more apparent than real since motivation should be thought to have nonconceptual evaluative content. However, the present paper is not the place to pursue this idea. ${ }^{27}$

There is also support for a hybrid model in the literature. This model agrees with the assertoric model that motivation can be associated with evaluative content, but disagrees with its assimilation of motivation to an evaluative perception or belief. A version of this model might hold that agents desire the good as such, or aim to do what is good. Talbot Brewer could be interpreted as falling into this camp. ${ }^{28}$ At any rate, since the hybrid view appeals to evaluative content, in

Here I use "presentation” and its cognates in Brentano's sense as a merely contentful state that of itself entails no commitment to the truth, appropriateness, etc., of its content, and which can be taken up into an attitude that does entail some such commitment. See Brentano, Psychology from an Empirical Standpoint, 61-63.

23 Raz, "Agency, Reason, and the Good"; Buss, "What Practical Reasoning Must Be If We Act for Our Own Reasons"; Gregory, "The Guise of Reasons."

24 Davidson, "Intending," 86.

25 Oddie, Value, Reality, and Desire; Hawkins, "Desiring the Bad under the Guise of the Good."

26 See for instance Velleman, "The Guise of the Good"; Schroeder, "How Does the Good Appear to Us?"; Saemi, "The Guise of the Good and the Problem of Over-Intellectualism.”

27 I investigate just such a view in Boswell, "Affect, Representation, and the Standards of Practical Reason," ch. 4. See also Oddie, Value, Reality, and Desire, 80; Hawkins, "Desiring the Bad under the Guise of the Good." 
principle it possesses the same content-based resources as the assertoric view to account for the intelligibility of action, so I will not discuss it separately here.

\section{INTELLIGIBILITY}

In this section I first present a brief tour of the notion of intelligibility with the aim of thereby rendering IC, as well as GG's explanation of it, prima facie plausible. I then argue that a proper understanding of intelligibility defuses an objection from Kieran Setiya.

I should note that both supporters and critics of the intelligibility motivation have, at times, targeted other notions of intelligibility than the one I sketch below. Most notably, although the notion of intelligibility at issue here owes a great deal to Anscombe, it owes yet more to Warren Quinn. Anscombe holds that statements or agents under a certain description (typically as wanting something) are intelligible or not absolutely, and the notion of intelligibility she has in mind seems to be analogous to that according to which "Colorless green ideas sleep furiously" is not intelligible. ${ }^{29}$ Regrettably, considerations of space prevent me from giving this interpretation its due in this paper; suffice it to say that I think the more compelling version of the intelligibility motivation relies on intuitions not about what is interpretable as an agent, as Anscombe's does, but about our relationship to our own actions.

\subsection{Intelligibility of an Action to an Agent}

The notion of intelligibility at play is specific in that an action is intelligible to its agent only if the agent has some consideration in mind, generally a property thought to be instantiated by the action, in virtue of which it is intelligible to him. Take for instance Quinn's infamous Radio Man, who finds himself in a bizarre functional state that causes him to turn on any radio at hand-though he does not turn them on in order to hear anything, or indeed in order that anything else happen. It is just something that he is disposed to do. ${ }^{30}$ What is most conspicuously lacking in Radio Man is an idea of what is to be accomplished by his

29 See, for example, Anscombe, Intention, 14, 19, and 26; cf. MacIntyre, "The Intelligibility of Action," 64. Vogler (Reasonably Vicious, 49, 51) and Raz ("The Guise of the Bad," 11-13) seem to rely on Anscombe's notion while Raz ("Incommensurability and Agency," 118) and Tenenbaum (Appearances of the Good, 33-35) seem to avail themselves of both Quinn's and Anscombe's notions of intelligibility.

Quinn, "Putting Rationality in Its Place," 32. 
turning on radios-what the point of it is. ${ }^{31}$ But what reason for acting could he have if he has no idea what the point of the action might be ${ }^{32}$

Because it concerns the sense the agent made of her action, the notion of intelligibility is also agent-relative and actual: IC requires of any action for a reason that its agent actually saw - that is, actually had mental access to-some point to the action. In this sense, the action is not intelligible in virtue of falling under some type that would be intelligible to someone else in other circumstances, nor in virtue of being intelligible in some absolute sense.

To be sure, an intelligibility requirement built solely on this idea-that in order to $\phi$ for a reason there must be some consideration the agent takes to be the

31 GG insiders may recall that Quinn ("Putting Rationality in Its Place") focuses a little less on the intelligibility of action than on the thesis that desires must be evaluative if they are to rationalize action. Some philosophers have also taken desire's rationalization of action to be a main explanatory payoff of GG. One might wonder why I focus on intelligibility, then. One difficulty is that "rationalization" is used in different ways: Is a rationalization (1) an explanation of an action in terms of the agent's own reason for it (Davidson, "Actions, Reasons, and Causes," 3)? Or does something rationalize action just in case it (2) makes that action rational, or alternatively, (3) grounds or "gives" the existence of a pro tanto or prima facie reason for it (Quinn, "Putting Rationality in Its Place," 40)? All these interpretations pose problems for GG's potential to explain how motivation rationalizes action. In brief, whether it is plausible to claim that only evaluatively construed motivations contribute to the rationality of action, as on (2), depends on the correct theory of rationality, and as for (3), many GG theorists hold that desires track reasons but do not ground them. For (1), GG can indeed explain why the agent does not act on a reason of her own when her action does not appear good to her, but it does this precisely by using GG to explain the unintelligibility of such action, as in Quinn's article. So I regard the intelligibility requirement, and GG's explanation of it, as more fundamental than and key to GG's explanation of how desire (or certain motivations) rationalizes action.

32 A referee pointed out that it is not at all clear that Quinn accepts IC. After all, does Radio Man not walk across the room for a reason-so as to turn on the radio-in spite of the unintelligibility of doing so? In a sense the criticism is fair. Quinn is interested not in the conditions for an action's being done for a reason but for its having a rationalization, where "rationalization" is interpreted as (3) and not (1) (see previous note), and so there are not sufficient grounds for counting Quinn as endorsing IC. On the other hand, nor are there sufficient grounds for counting Quinn as rejecting it. That would require Quinn to hold that one can act for a reason without having an attitude that gives one's reason for acting, since for Quinn an attitude's giving a reason for acting entails the existence of that reason, and Quinn also holds that there is no reason for Radio Man to take means to turn on radios ("Putting Rationality in Its Place," 32-33). This in turn undercuts the necessary connection between practical thought and the good that Quinn is trying to draw ("Putting Rationality in Its Place," 29-30). A more coherent position for Quinn would be that all action for a reason is for a (at least prima facie) reason that rationalizes that action, but that mere goal-directed action is not necessarily done for a reason. Regardless, this exegetical point is not crucial to the argument of the paper; the goal of this section is to draw out the intelligibility motivation as it has generally been understood. 
case and in light of which ping is intelligible to them-is neither controversial nor interesting. ${ }^{33}$ Quite plausibly it falls out of the very concept of acting for $a$ reason that one have at least some reason in mind in acting. But the special interest in the GG theorist's conception of intelligibility is that not just any feature, consequence, or aspect thought by the agent to be instantiated by the action suffices to make that action intelligible to the agent:

Suppose, for example, that you notice me spray painting my shoe. You ask why I am doing that, and I reply that this way my left shoe will weigh a little more than my right. You ask why I want the left shoe to weigh a little more. Now suppose I just look at you blankly and say, “That's it." I seem not to understand your puzzlement. You grasp for straws. "Is this some sort of performance art, on the theme of asymmetry?" "No." "Is someone going to weigh your shoes as part of some game?" "No. Why do you ask?"34

Here it is clear that there is an oddness about the Shoe Painter's explanation even though they have correctly identified a plausible consequence of spray painting their shoe.

Thus there appear to be substantive constraints on intelligible-making properties. Being instrumental to something one is compelled to do does not make an action intelligible. Nor does thinking of one's action as possessing a thin normative property, such as being what one should do as such, render it intelligible, as Dave's example shows. ${ }^{35}$ So if indeed action for a reason must be intelligible to its agent, what explains why such action can occur under the guise of its instantiating certain properties and not others? GG proposes just such an explanation: the property must be, as Anscombe puts it, "one of the many forms of good," i.e., a particular or substantive evaluative property or kind of good. ${ }^{36}$ Thus we arrive at GG's account of the intelligibility of action: an action is intelligible to its agent

See Schapiro, "The Nature of Inclination," 235-59, for a longer, nuanced discussion on this point. Schapiro takes Quinn's argument to ultimately show that thinking of desires as dispositions neglects their crucial role as proposing courses of action.

Clark, "Aspects, Guises, Species, and Knowing Something to Be Good," 234-35.

I consider an objection to this interpretation in section 2.2 below.

Anscombe, Intention, 77. For echoes of Anscombe on this point, see Quinn; "Putting Rationality in Its Place," 41-42; Johnston, "The Authority of Affect," 189-90; and Vogler, Reasonably Vicious, 51. For the sake of simplicity, I write throughout of specific evaluative properties or kinds of good. Guise of Reasons and Guise of Ought theorists need to find equivalent notions. However, these are ready at hand. Just as it is plausible that there are distinct kinds of value, it is also plausible that there are distinct kinds of reasons and oughts, such as moral, prudential, and aesthetic. 
just in case, and because, it seems to the agent to instantiate or promote a substantive value-property. Together with GG's claim that an action done for a reason must be seen by its agent as good, this account of intelligibility can explain why IC is true - that is, why action for a reason must be intelligible to its agent.

Before moving on to Setiya's objection, let me address a worry about this understanding of the relation between GG and the intelligibility motivation. There are two parts to this explanation: the first is the account of the intelligibility of action in terms of seeing that action as good, and the second is the claim that this account and GG together can explain why IC is true. One could imagine both steps going differently, however. After all, GG is compatible with constructivist approaches that explain the good in terms of features of rational agency, or indeed with a no-priority view about the relation between rational faculties and the good. ${ }^{37}$ Since it is furthermore plausible to hold that finding an action intelligible belongs to rational agency and is an aspect of our rational faculties, it would seem possible that a GG theorist could attempt to explain what it is for an agent to see her action as good in terms of what she finds intelligible, or to hold that necessarily an agent sees as good just what she finds intelligible, without assigning explanatory priority to either notion. Such a theorist could then deploy such an account, together with IC, to explain GG. On this way of understanding the problem, we begin with the question, "Why must actions done for a reason be seen as good by their agents?" and the response is that to see an action as good just is to find it intelligible, and action for a reason must be intelligible to its agent. ${ }^{38}$

But the affinity between constructivism and the seeing-good-to-intelligibility direction of explanation is more apparent than real. It is one thing to explain the good in terms of the possibility of finding an action an intelligible object of choice, and another to explain seeing something as good in terms of its being made an intelligible object of choice. At any rate, whatever the GG theorist's account of the relation between rationality and the good, it seems to me that she faces considerable pressure to understand the intelligibility of action in terms of seeing good in the action. First, an explanation in the other direction threatens to reduce away the normative guise that is essential to GG: if the GG theorist tells us that agents must see as good all actions they do for a reason, but then clarifies that by "see as good" she means "find intelligible" or "make sense of," then it is not clear that she has told us anything particularly controversial. Even as

See Tenenbaum, Appearances of the Good, ch. 3, for a Kantian view that is at least consistent with constructivism, and Raz, "Reason, Rationality, and Normativity," 86, for the latter, no-priority view.

38 Thanks to a referee for pressing me to address a possibility along these lines. 
staunch a GG opponent as Setiya could in principle adopt this theory by in turn understanding the intelligibility of action in terms of the agent's having a causal-historical explanation for it. ${ }^{39}$ Thus, this direction of explanation threatens GG with triviality ${ }^{40}$ And second, the no-priority view seems to me an option of last resort, insofar as it posits an unexplained necessary connection between seeing good and finding intelligible. ${ }^{41}$

\subsection{Setiya's Objection}

Once we clarify that seeing an action as good can render it intelligible only when an agent has a particular kind of good in mind, we can neatly sidestep an otherwise worrisome objection Kieran Setiya first raised to GG's explanation of IC. The objection centers around the fact that merely noting that someone's action was performed under the guise of the good does not suffice to make the action intelligible. Setiya's version of the objection alludes to a famous line in Raz, which is intended to illustrate the idea that rules of rationality constrain choice, and that one of these constraints is that one can only choose for what one takes to be a good reason: "I cannot choose to have coffee because I love Sophocles," he writes. ${ }^{42}$

To this Setiya responds that merely conceiving one's options explicitly under the guise of the good need not make them any more intelligible, and he illustrates the point with the following dialogue:

"She is drinking coffee because she loves Sophocles."

"What? That makes no sense at all."

"Oh yes it does! She thinks it is a reason to drink coffee."43

I think Setiya's dialogue is best taken as illustrating just what Dave's story does: it sure seems possible —indeed, actual, given Dave—-for someone to think that an action would be good, or what she ought to do, or what she has reason to do, etc., and yet for this not to make the action any more intelligible. But, given section 2.1, the GG theorist can plausibly reply that what has gone wrong here is that we

Setiya, Reasons without Rationalism.

I discuss a related triviality worry for GG in greater detail in Boswell, "Affect, Representation, and the Standards of Practical Reason," 31-37.

1 Once we have established that the GG theorist should explain intelligibility in terms of seeing good, we still face the question of whether we might instead see this account together with IC as supporting GG. However, the choice between the two is a matter of rhetorical strategy and would not affect the central conclusions of the paper.

2 Raz, "When We Are Ourselves," 8.

Setiya, "Sympathy for the Devil," 97. 
are not given any kind of good under whose guise the coffee drinker drinks. If we were told that she is drinking coffee because she thinks this honors Sophocles, we may be confused as to why she would think that. But we would then appreciate her goal of honoring a literary figure, and thus find it intelligible as she does. ${ }^{44}$ Thus, Setiya's objection does not undermine the intelligibility motivation for GG, once this motivation is properly understood.

Derek Baker has recently pressed a version of the same objection to views of desire as evaluative perception-like seemings, and it fails for the same reason. ${ }^{45}$ Taking up a Radio Man-like example from Johnston, he asks us to imagine someone who acts on a blind urge to turn a knob counterclockwise. ${ }^{46}$ Baker grants that the action will strike its agent as unintelligible, especially if she believes it not good to turn it, but he then supposes the same agent now acts on a perception-like feeling that there is a reason to turn the knob, even though she knows this feeling to be inaccurate. Baker objects that this addition of a seeming of a reason does not make the turning any more intelligible. But of course, we can now see that this is not an effective test of the intelligibility motivation. For that we would need to suppose that the agent feels there to be a specific kind of reason to turn the knob, even though she disbelieves this feeling. So let us suppose instead that the agent desperately feels that by turning the knob she will be free of the dungeon in which she is trapped, though she knows the door is locked. Does this feeling, a misleading anticipation of freedom, make sense of her turning the knob? The answer is clearly yes. She can see a point to her turning, though the point goes beyond her own hope of fulfilling it.

So it appears that there are guises of the good such that acting under them does not suffice for action for a reason. Why might this be so? By returning to the groundwork of GG laid out in section 1, I think we can glimpse why acting merely under the guise of normative notions like "ought," "reason," "good," or "desirable" will not suffice. According to GG, there is a constitutive, formal aim of whatever motivations it holds are appearances of justificatory force: they function to register or reflect ways in which actions may be justified. Because GG holds that these appearances also guide one to act because of the justificatory

One might think that Setiya's objection fails for a different reason, that, quite generally, possessing the testimony that $P$ need not make $P$ intelligible to one. I may, for instance, accept that some mathematical theorem I do not understand is true simply because Professor Conway told me it was. Quite plausibly, this general truth relies on a distinct kind of intelligibility, that of simply not fully grasping a proposition. But in Setiya's dialogue we are to imagine that the interlocutor does understand the last line, and finds the purported reason unintelligible nonetheless. Baker, “The Abductive Case for Humeanism over Quasi-Perceptual Theories of Desire," 20. Johnston, "The Authority of Affect," 189-90. 
force registered or reflected in them, it follows that action itself is constitutively regulated by justificatory force, at least when it is done for a reason. But one's reason for acting cannot reflect merely that the action meets this constitutive aim, any more than one's reason for believing a proposition can be merely that it is true. (Supposing, of course, that belief is constitutively regulated by the norm of truth.) A genuine reason must offer intelligible support, and intelligible support cannot be so directly question-begging. A reason for acting must reflect a particular way in which the constitutive aim of action for a reason is met, just as a genuine reason for believing must reflect a particular way in which the constitutive aim of belief is met. ${ }^{47}$ Now, as we also saw in section 1 , the notions of what one ought to do, what one has reason to do, and what is good to do, are simply different candidates for this formal aim of action. Their suitability to playing this role of the formal aim of action is thus precisely what prevents action merely under their guise from rendering action for a reason intelligible.

Let me turn to three objections to this strategy of response to Setiya. First, there is an alternative way of understanding the import of cases like Dave, the Shoe Painter, and drinking coffee for love of Sophocles. One might think that these cases do not show thin normative concepts themselves incapable of rendering action intelligible, and instead show only that their ability to render action intelligible is conditional on these concepts being intelligibly applied in a given case. This view holds that the Shoe Painter's action is unintelligible not because she saw no specific kind of good that painting her shoe would accomplish (taking for granted, of course, that making her shoe a little heavier is not of itself good), but because she could not intelligibly take making her shoe a little heavier as itself a reason for painting the shoe. The idea is that taking anything to be a reason for an action suffices to make that action intelligible, so long as the thing taken to be a reason can intelligibly be so taken. Indeed, there is one way of reading Raz's discussion of drinking coffee for the love of Sophocles on which this is the very moral that he offers: his point may be that there are substantive constraints on what could be taken to be a reason for choice or on how an action

One might object that there are many cases in which a good reason for believing $P$ is simply that it seems to one that $P$ is true; perhaps, indeed, we cannot rebut skeptical arguments without a like entitlement. Is this not a question-begging reason for belief? (Thanks to a referee for this objection.) But there are two ways to read the offered reason, that "it seems to one that $P$ is true." On the first, less plausible reading, one's reason is simply that $P$ is true, as it seems to one to be the case. That is directly question-begging, and not an intelligible reason for believing $P$. On the second, one's reason is that one has a seeming as of $P$ being true. That is an intelligible reason for believing $P$, but it is also not directly question-begging insofar as it appeals to a state distinct from belief in $\mathrm{P}$ that may well confer justification on it. 
may be seen to be good if it is to be done for a reason, and that on his view these constraints derive from a theory of value. ${ }^{48}$

However, I fail to see how making one's shoe a little bit heavier could simply be conceptually ineligible to be taken as a reason for painting one's shoe. Indeed, the interlocutor in the Shoe Painter example suggests two contexts that could make this a perfectly intelligible reason for that action - and it bears noting that both contexts (a sports competition, an artistic piece) plausibly render the action intelligible by connecting the reason to a specific kind of good (winning a game, aesthetic value). The situation is even worse for the objector once we turn to other thin normative concepts. Is it really plausible to suppose that the unintelligibility of Dave's kneeling in the street in front of the oncoming car is due to the fact that it is simply unintelligible to think that one should kneel down in the street in front of an oncoming car? On the contrary, it is clear that we can make such a thought intelligible by connecting it to a kind of good, for instance by supposing that Dave thought kneeling before the car the only way to save the lives of five children tied down to the road farther ahead. The objector may after all be right that seeing a thin good in an action is conditionally sufficient for rendering the action intelligible, but the condition involves the agent's seeing a specific kind of good in the action.

Second, one might try to extend Setiya's objection by finding cases in which an agent does see some substantive kind of good in acting but also in which that action is not intelligible to them. To see the idea, suppose that a moderate form of judgment externalism is true-in particular, that moral judgments do not necessitate motivation. One might then think that caring about something, and not merely judging it good in some specific way, is what makes action intelligible. ${ }^{49}$ Imagine a miser who always judges it charitable to give bonuses to his employees, but who is left entirely cold by the idea, and so-the objection runs-does not find the prospect of actually giving out a bonus intelligible. If that is possible, GG fails to give a sufficient condition for intelligibility.

To this the GG theorist should respond that GG is not committed to holding that every way of cognizing an action as good amounts to seeing the action as good in the sense relevant to intelligibility, just as GG is not committed to holding that any sort of motivation or action whatsoever occurs under the guise of the good. ${ }^{50}$ And indeed, there seems to be an important difference between abstractly assenting to the proposition that something would be the charitable thing to do and really getting, feeling, recognizing, or having a practical intuition of

48 Thanks to a referee for suggesting a response along these lines.

49 See Stocker, "Desiring the Bad" and "Raz on the Intelligibility of Bad Acts."

50 Tenenbaum, Appearances of the Good, 73-75, effectively makes the same point. 
its value, though different GG theories will have different ways of cashing this thought out. ${ }^{51}$ So a GG theorist could plausibly respond that the miser did not really see a substantive kind of value in bonus-giving in the relevant sense of "see," and that is why it was not intelligible to him..$^{52}$

Third, one might object that finding oneself with the inexplicable intuition that drinking coffee somehow honors Sophocles hardly makes more sense of drinking coffee than the bare intuition that one ought to drink it. What does the kind of good add $?^{53}$

I agree that thinking that drinking coffee honors Sophocles, absent further beliefs that rationalize this belief, is odd. But the oddness is that of having an odd theory about honor, and for the resolution of our puzzlement we require only some story of the agent's history that shows her to have arrived at this theory through familiar psychological mechanisms. This puzzlement contrasts with that about someone who thinks that some action just ought to be done, without any further idea as to its import-even supposing that they point to the promotion of some other nonnormatively described property as their claimed reason for acting. ("I am placing this book here because that way I will have seventeen green books placed horizontally on my roof, which seems like the number I ought to have.") Any historical explanation of this state of mind would still leave us saying, "That alone can't be his reason for acting, if he really has one." We cannot see how his action could be intelligible to him, absent some further story of how that action appeared to him to be related to some further, specific kind of good.

\section{AGAINST THE ATTITUDINAL MODEL}

Note that the assertoric model is well-positioned to account for the sense in which the intelligibility of action requires an appeal to specific evaluative properties. This is simply because it can hold that whatever motivations are appear-

51 See Johnston, "The Authority of Affect," 192-93, for an illustration of how what he calls "affective collapse" can lead an ongoing activity to resemble mere habit or automatic action, even if one still believes, in an abstract, non-affective way, that the activity is valuable.

Of course, other responses to this challenge are possible. One could deny that the miser ever fails to find bonus-giving intelligible, and that what changes is merely his motivation to do it. Tenenbaum (Appearances of the Good) argues against judgment externalism (as part of what he calls the "separatist thesis"), and so can deny the coherence of the supposition that the miser really believed bonus-giving good but did not find bonus-giving intelligible at all. Roughly, Tenenbaum's view implies that the miser finds bonus-giving only conditionally intelligible (Appearances of the Good, ch. 8).

Thanks to Stephen White for impressing on me the importance of this objection. 
ances of the good must have some such evaluative property as part of their representational content, with no expectation that the same good is part of the content of every motivation. Take, for example, the view that emotions are appearances of the good with evaluative content. This view can hold that fear presents approaching a growling dog as dangerous while anger presents retaliation as payback. Dangerousness and payback are just different values, and they make different sorts of actions intelligible.

In contrast, according to the attitudinal model it is constitutive of motivation (of whatever sort GG is concerned with) to $\phi$ that it presents-as-good $\phi$ ing, in much the same way that belief presents-as-true its content. Generally speaking, proponents of this version of GG hold that the motivation in question is desire, so for ease of exposition in discussing their view, below I frequently replace talk of motivation with talk of desire.

But it would appear that this reliance on a feature of presenting-as-good that is common to all desire is also what prevents the attitude model from accounting for the intelligibility of action. As we saw above, if GG is to explain the intelligibility of action, it must explain it by reference to the appearance to the agent of a particular kind of good or evaluative property. That was precisely what we needed to respond to Setiya's objection, above. Yet it is hard to see how the attitudinal model can deliver this. The attitudinal view cannot simply hold that we act under the guise of a thin notion of good, as in the case of a view that holds that any desire presents its content as choiceworthy, desirable, or what one should bring about, as such. For recall that if this were so then the attitudinal model would secure the intelligibility of desired action only if Dave's action is intelligible to him. After all, it appeared to Dave that what he should do is kneel down and be hit by the car, and nevertheless his action was not intelligible to him. Clearly it makes the action no more intelligible if we substitute "is desirable for me to do" or "is the choiceworthy thing to do" for "should do."

The attitudinalist thus needs to thicken up her notion of good. There are a number of conceivable ways to accomplish this, but one attitudinalist already appears to possess the resources to deal with this problem. According to Sergio Tenenbaum, desires not only present their contents as meeting the formal aim of desire, but they present it under a certain perspective. ${ }^{54}$ The perspective under which one desires is then to explain the particular way in which one's desiring is intelligible. The bare fact that Sue wants to damage Ms. S's boat does not intelligibly explain why Sue is throwing stones at it. But if we are told that Sue wants to damage Ms. S's boat out of envy, it appears we have been given an explana- 
tion that shows her stone casting to be intelligible. ${ }^{55}$ Other perspectives that can make certain actions intelligible include honesty, or being a cinephile, a gourmand, or a good parent—all of which can be plausibly understood as organized around specific kinds of good.

Here is a general version of the strategy at work. The attitudinal theorist is weakening the proposed analogy with truth in a certain respect. According to the story told in section 1, the connection between belief and truth is constitutive of and common to any belief, for all beliefs present-as-true their content. But perhaps token desires may present different substantive evaluative properties. Perhaps it is constitutive of desire that it present some good or other, even though no particular good may be required. Truth is one and good many, it might be said. Some such necessary connection between desires and specific evaluative properties is needed to overcome Setiya's objection, and it also seems to be what Tenenbaum is trying to secure.

Unfortunately, this connection is not ultimately available to the attitudinal theorist. I consider two formulations of this view. The first characterizes the connection between motivation and a specific evaluative property in terms of an adjective embedded within a verb: a token appetite presents-as-tasty a treat, say. The second, Tenenbaum's way, characterizes it adverbially: Sue desires enviously. Against the first I argue there is no obvious, good reason to think that it characterizes an aspect of an attitude as opposed to its content, and that there is reason to think the opposite. Against the second, I argue that it cannot secure the needed mental access to the specific good that GG requires. This leads me to advance in the final section a general argument against attitudinal views.

\subsection{The Adjectival Formulation}

What is an attitude? Orthodoxy has it that it is a relation between a subject and a content, usually a propositional content. ${ }^{56}$ Most of the disagreement on this question is over the deeper nature of this relation. Staying at the level of commonly accepted platitudes, we could say that the content of a mental state gives what the mental state presents to the mind, what it is about, and the attitude provides how that content is presented, or the way in which the subject takes that content or that presentation.

So when the attitudinal theorist tells us that the desire for a treat presentsas-tasty the treat, should we take her at her word that she has characterized an aspect of the attitude of desire? Against this, note that nearly all the substantive, intelligible-making goods, such as health, success, beauty, and tastiness, are

55 Tenenbaum, Appearances of the Good, 43 (Tenenbaum's example).

56 E.g., Fodor, "Propositional Attitudes," generalizing slightly. 
properties of the things, states of affairs, and people that our motivations are concerned about. They are not properties of representational entities like propositions. If your appetite for the treat presents-as-tasty the treat, then it seems your attitude can also be expressed by saying that you take it as true that the treat is tasty. You in some way attribute tastiness to the treat-that is why it is intelligible to you to eat it. And of course, we would naturally think that "tasty" figures in specifying the content of the attitude when expressed this way. But it is distinctive of attitudinal views that the good is not supposed to play a role in motivation by figuring in the content of a mental state.

These reflections point to a sufficient condition for construing a property $P$ as figuring in the content of an attitude-type $A$ :

AC: If attitude $A$ presents- $X$-as- $P$, where (in a token case) $X$ is what $A$ is about and $P$ is a property that $X$ could instantiate, and $P$ is not exclusively a property of a representational entity like a proposition, then $A$ 's content (in that token case) is that $X$ is $P$.

This principle has the great benefit of not misconstruing the contents of beliefs and perceptions, contrary to an accusation that Karl Schafer has brought against assertoric views. ${ }^{57}$ Here is one way to see the worry, and how AC avoids it. As noted above (section 1.1), beliefs present or regard their contents as true, but the mere fact that a belief that $X$ presents $X$ as true cannot suffice for the content of that belief being ( $X$ is true). If that were true, the belief that $X$ would also be the belief that ( $X$ is true), since the content of a belief is what follows the complementizer "that" in "the belief that." But as a belief, it would also present ( $X$ is true) as true. Thus a regress begins. So it cannot be a general truth about attitudes that, if an attitude presents- $X$-as- $P$, then $P$ is part of its content. From this it would appear that appealing to the fact that motivation presents an action as good in support of an assertoric view is simply special pleading.

AC does not entail that truth is part of the content of belief, however, for the simple reason that if belief presents $X$ as true, then $X$ must be a proposition, and a proposition is a representational entity. Nor are propositions what most beliefs are about; they are about taxes, fish, and all other things under the sun, most of which are not truth-apt.

AC also captures why the formal objects of a number of attitudes are best construed as part of their content. Fear of a dog presents the dog as dangerous, and some find it natural to say that the content of this fear is that the dog is dangerous; AC explains why. ${ }^{58}$ Or, take the class of beliefs about people's hairiness,

57 Schafer, "Perception and the Rational Force of Desire," 269.

58 Those most inclined to find this intuitive are emotional perceptualists like Tappolet (Emo- 
and suppose that this class forms a type of attitude. We may then note that my belief that Steve is hairy presents-as-hairy Steve. But AC explains why we should not construe attitudes in this class in terms of a primitive presenting-as-hairy attitude that takes people as contents. "Hairy" qualifies Steve, not the manner in which he is represented to me. ${ }^{59}$

AC has the effect of limiting what properties the attitudinalist may substitute for $P$ in an attitude $A$ that presents- $X$-as- $P$ to those that either cannot be instantiated by whatever the attitude is about, or those that, like accuracy and the alethic modes, are exclusively properties of representational entities. This might seem unnaturally disjunctive. It may also seem that the latter restriction in particular hides the bone of contention, since what is at issue is whether normative properties such as the good-which surely do not exclusively apply to representational entities - can ever be substituted for $P$ without figuring in the content of $A$. But there is, I believe, an attractive, general, and altogether orthodox picture of the relation between attitudes and their content that supports AC. According to this picture, the content of an attitude "gives" what the attitude is about by representing what the attitude is about, and when $A$ presents $X$ as $P, P$ quite generally figures in $A$ 's content-except where $X$ is the content of $A$, and $P$ is taken as modifying the manner in which that content, qua representation, is held before the mind. But where $P$ functions to modify what the attitude is about (taxes, fish, etc.), it is difficult to see how $P$ could do so without figuring in the content of the attitude itself, at least so long as we hold on to our platitudes about the distinction between attitude and content. Alternatively, the attitudinal theorist could reject the assumption that contents of attitudes are representational, but this seems to me to be extraordinarily costly. ${ }^{60}$ Thus, to reject AC the attitudinalist would need to construct a different conception of the relation between attitudes and their content.

The attitudinalist may at this point object that there is a difference between

tions, Values, and Agency) and cognitivists like Solomon ("Emotions and Choice") and Nussbaum (Upheavals of Thought). Emotional attitudinalists deny this, however; see Deonna and Teroni, The Emotions.

59 It must be granted that AC's implications on other attitudes, particularly attitudes of confidence and doubt, are less clear. A suspicion that $X$ presents $X$ as somewhat likely. But does it present an event as likely, or does it present the proposition that $X$ as likely true? I am inclined toward the latter, since the relation between probability and credence is broadly similar to that between outright belief and truth. But there is no space to pursue the issue here.

60 In brief, it seems to me that such views either cannot explain the failure of existential generalization from attitudinal contents or must rely on a mysterious relation to mere possibilia. But obviously, the debate on this question is long and intricate, and cannot be settled here. 
an attitude that presents- $X$-as- $P$ and the attitude of taking it to be true that $X$ is $P$, for the former can be possessed by a creature without the concept of $P$ while the latter cannot. ${ }^{61}$ But the principle this objection implicitly relies on-that one can only possess an attitude with content $C$ if one possesses all the concepts required for a specification of $C$ - is a rather contentious one insofar as it rejects the possibility of nonconceptual content. ${ }^{62}$ Moreover, the attitudinalist would owe us a justification for thinking that we can say that the creature presents- $X$ as- $P$ even though she objects to saying that it takes it to be true that $X$ is $P$. What could the difference be?

Now, in the foregoing I assumed that the "presents-as-good" locution is to be understood in terms of an attribution of a specific kind of goodness. With this assumption in place, AC is particularly intuitive. Some may seek to object to this assumption once it is seen that it leads to a rejection of the attitudinal view. However, if we do not understand the locution this way, it is hard to make sense of it, especially as an articulation of a GG view. What could it mean to take-as-beautiful a painting, if not to attribute beauty to it? What sort of manner of response to a content would that be? The attitudinalist cannot say that it means that one takes a certain kind of pleasure in the painting. For, to avoid circularity, she would then need to provide a non-attitudinal evaluative account of pleasure in order to secure GG. It is not clear to me how she could do this without ascribing evaluative content to pleasure, in which case the view would be a convoluted version of the assertoric strategy. Perhaps then it means responding to the painting in whatever manner is appropriate to a beautiful object. ${ }^{63}$ But why would that manner necessarily imply that the subject has mental access to the relevant good, as GG requires ${ }^{64}$ Lastly, if the adjectival locution is not understood as implying an attribution of goodness, it does not seem to allow the possibility of motivation's being mistaken about the good. Yet the ability of GG to secure the

61 Thanks to Christine Tappolet for this objection.

62 Nonconceptual content is frequently attributed to perceptual experiences and emotions. For an overview, see Bermúdez, "The Distinction between Conceptual and Nonconceptual Content."

63 As noted above, many attitudinal theorists take the presenting-as-good character of desire to be primitive. The responses just considered are unavailable to these theorists, who are unable to explain this character in more basic terms and thus face extraordinary difficulty explaining why "good" should be thought to characterize an aspect of an attitude apart from its content.

64 Note the contrast with belief here: it is not at all clear that belief involves mental access to the truth of a proposition over and above access to the proposition itself. In believing, one is generally guided by defeasibly justified inferences, but this guidance need not take the form of tracking appearances of truth. 
sense in which one's motivations can be mistaken is often considered one of the explanatory benefits of GG. ${ }^{65}$

Thus this first version of the attitudinal view of GG could indeed make sense of how the appearance of specific kinds of good makes actions intelligible-but it can do this only by surreptitiously dropping the attitudinal view and taking up the assertoric view. Briefly put, if a mental state of presenting- $X$-as-good is to make action intelligible, it needs to be understood as attributing goodness to $X$, and it can only do this if goodness figures in the content of the state.

As we see in the next section, the second version of the attitudinal view faces a different but complementary problem: it cannot account for the way in which acting under the guise of the good involves the agent's mental access to the good.

\subsection{The Adverbial Formulation}

On Tenenbaum's view, Sue's desire to throw rocks at Ms. S's boat has an adverbial characterization: she desires enviously to throw rocks at it. Judging by Tenenbaum's development of the view, it is clear that this is a refinement of the attitude strategy. In order to act out of envy Sue need not have the explicit aim of acting out of envy; envy need not enter into the content of her mental states. She does not necessarily desire to be envious. Rather the envy is held to figure in the manner in which the world and practical possibilities appear to her. She enviously desires the destruction of the boat, and this manner of appearance is made manifest in the options for action she takes seriously, her irritability toward praise of the boat, the comments she makes about Ms. S, etc.

However, it turns out that this maneuver does less good for the attitudinal theorist than she might have hoped. Clearly there are such modes of acting and desiring, and we can appeal to them in order to give third-personal rationalizing explanations of agents' actions. But to say that an agent acted from a certain perspective is not always to explain the action in terms of the agent's point for that action. Sue might be self-consciously envious, but it is also possible that she is completely ignorant of her own enviousness. Her conscious motivations may have been limited to thoughts that Ms. S was fundamentally at fault, and that she needed to be taken down a peg. One can easily imagine a friend confronting Sue about her enviousness and Sue, upon realizing the truth about herself, coming to terms for the first time with her own envy. This reckoning would be rather like Freudian Dave's discovery in psychotherapy that he was motivated to lie down in the street by his repressed fear of failure: both agents may be said to have learned about their reasons for acting, but not in the sense of "reasons

65 See Tenenbaum, Appearances of the Good, as well as Baker, "The Abductive Case for Humeanism over Quasi-Perceptual Theories of Desire," for critical discussions. 
for acting" we are looking for, since in both cases the motivation (envy or fear) was opaque to the agent. ${ }^{66}$ Thus, while it may be that when one acts for a reason one acts under a perspective on the good, this latter cannot by itself explain the intelligibility of action for a reason.

Tenenbaum's best reply might be to make a tactical retreat. Conceivably he could admit that desiring or acting under an unconscious perspective like Freudian Dave's fear of failure does not make an action intelligible to its agent, but conscious perspectives do. The view is tempting, but it only reveals the fatal flaw with the attitudinal approach. For what could consciousness provide to intelligibility except further content? To hold otherwise would amount to an extreme kind of adverbialist treatment of perspectives, in the sense derived from the philosophy of perception. ${ }^{67}$ Perhaps to be motivated consciously under the perspective of courage is, in being motivated, to be presented-to-courageously, where being presented-to-courageously is a non-intentional modification of a subject. But the absence of any relation to an intentional object or content of experience-say, to a desired action that might be courageous if one were to perform it-is precisely what renders this view incapable of capturing how awareness of specific evaluative properties renders action intelligible. ${ }^{68}$

\subsection{Content Makes Actions Intelligible}

We have come at last to the fundamental reason attitudinal theories fail to capture the intelligibility of action, which is that intelligibility requires relation to a

Indeed, Tenenbaum seems to acknowledge that the perspective under which one acts can sometimes be opaque to the agent; see Tenenbaum, Appearances of the Good, 50.

67 Ducasse, "Moore's Refutation of Idealism," 252-53; Chisholm, Perceiving.

68 Dokic and Lemaire ("Are Emotions Evaluative Modes?") raise a similar problem for the view that emotions are evaluative modes. This point against the attitudinal theory mirrors an influential critique of perceptual adverbialism, the many properties problem, which holds that this latter cannot account for the intentional structure of experience (Jackson, Perception). For a somewhat closer analogy, see Martin ("Setting Things before the Mind"), who argues that adverbialism cannot account for the fact that we are aware of our experiences through awareness of their intentional objects. However, there is at least one major reason to think that the present problem is much worse for the attitudinalist than these problems are for the adverbialist. Perceptual adverbialism is motivated by a desire to avoid reference to objectionable entities like sense data. But this motivation is not incompatible with attributing genuine intentional content to experience, for adverbialism can be interpreted as an alternative account of intentionality that still attributes content to experience, albeit in a deflationary way. (See Kriegel, "The Dispensability of (Merely) Intentional Objects," for an example of this strategy.) The attitudinal version of GG, however, needs to avoid reliance on content in explaining the good's contribution to intelligibility. 
content, which in turn is precisely what attitudinal theories reject. We can make this thought explicit in the following argument:

1. IC: If an agent $\phi s$ for a reason, then $\phi$ ing is intelligible to her.

2. If an agent $\phi$ s for a reason, then $\phi$ ing is intelligible to her in virtue of a state of mental access to a (apparent) kind of good possessed by $\phi$ ing.

3. If $\phi$ ing is intelligible to an agent in virtue of a state $S$ of mental access to something, then $S$ is a state of consciousness of that thing.

4. If $S$ is a state of consciousness of $X$, then $X$ figures in the content of $S$.

5. So, some kind of good figures in the content of the state that makes action for a reason intelligible.

Premise 2 captures how GG explains IC: intelligibility is to be explained by a state of mental access to a kind of good. Freudian Dave's case is extremely good evidence that unless this state gives conscious access to a kind of good, an agent does not have the right kind of mental access to the (apparent) good of his action, and thus this state cannot explain the intelligibility of action. This justifies premise 3 . Premise 4 is supported from what is quite generally taken as a starting point in the philosophy of mind: the content of consciousness just is whatever we are conscious of. From this we need to go only a little further and hold that the content of a state of consciousness of something is just that of which it is a state of consciousness. ${ }^{69}$

From these premises, the conclusion in 5 follows. But 5 contradicts attitudinal views that aim also to account for the intelligibility of acting, according to which goodness need not figure in the content of desire. (Importantly, note that we could replace "kind of good" in this argument with a term denoting any property that is held to make action intelligible, and the resulting conclusion would still follow. Hence, the argument shows that attitudinalist-construed accounts of the intelligibility of action in general fail.)

The substantially new premises in this argument are 3 and 4 . Because premise 4 is the more innocuous of the two, it will be best to concentrate on objections to premise $3 \cdot{ }^{70}$

69 It must be admitted that premise 4 is more contentious when certain varieties of self-consciousness are at issue. When I am struck with an awareness of a leg that is mine, or that my visual point of view differs from yours, must I figure in the content of such awareness? Fortunately, what is at issue for the present argument is consciousness of actions and their properties, not the self directly, nor even whose actions they are. With that granted, premise 4 can be understood as tacitly excepting self-consciousness and the argument will go through. (Thanks to Jens Gillessen for raising this issue.)

70 Of course, attitudinal theorists are free to define a notion of content on which premise 4 is false. However, this still leaves a very intuitive notion of content, expressed in that premise, 
One thing to note about premise 3 is that at this point in the dialectic, the attitudinal theorist appears bound to accept it, for they need it to avoid predicting that Freudian Dan's kneeling is intelligible to him. Nevertheless, the attitudinal theorist might try one of two ways out of this corner.

The first is to object that premise 3 takes the perceptual analogy that GG invites far too seriously. Perhaps to say that a motivation presents its action as good just is to say that it has an action- or intention-rationalizing Fregean force. ${ }^{71}$ This implies nothing about the content of that motivation. Furthermore, to capture the way in which intelligibility is specific, we could postulate as above (section 3 ) that different motivations or perspectives rationalize different kinds of actions. Desiring under the perspective of courage rationalizes bold actions, say, while desiring under the perspective of envy rationalizes spiteful actions.

However, whatever the attractions of this view, it is not at all clear it is a GG view. GG explains the rationalizing power of motivation in terms of motivation's relation to an appearance of the good, but this alternate view characterizes appearances of the good in terms of rationalizing motivations. This threatens GG with triviality, since it is uncontroversial to claim that when one acts for a reason one acts on a motivation that rationalizes that action. ${ }^{72}$ Furthermore, the notion of having mental access to the good is purely honorific on this view, amounting to no more than being in a state that in fact rationalizes action. It is hard to see how this would entail an epistemic state-unless, of course, we then explained rationalization in terms of mental access to the good.

The second strategy is to search for less than fully conscious attitudes that nevertheless contribute non-instrumentally, and not in virtue of their content, to the intelligibility of action. The clause "non-instrumentally" is crucial, since the above argument (and specifically premise 2) is consistent with unconscious states being causally responsible for the intelligibility of action, for GG offers a theory of what intelligibility consists in. Suppose that my name is Woolstonecraft, and that at work I overhear two low voices plotting against Woolstonecraft. To save my skin, I immediately decide to foil their plans. My knowledge that I am Woolstonecraft is crucial to the intelligibility of foiling their plans, and I do not need to consciously rehearse it for it to have this effect. But it is not what makes foiling their plans intelligible to me, for that function is served by the rec-

for which it will be true that intelligibility requires goodness to figure in mental content. So for an attitudinalist who is determined to reject this premise, the burden will be on her to develop and defend the importance of this different notion.

71 Schafer, "Perception and the Rational Force of Desire," 275-77.

72 Recall that we uncovered a similar triviality problem above (section 2.1) when discussing the possibility of understanding seeing an action as good in terms of finding it intelligible. 
ognition that self-preservation demands that I foil their plans. My unconscious knowledge is simply a causal antecedent of that recognition.

So what kinds of non-conscious states could contribute non-instrumentally to the intelligibility of an action? Here are two salient possibilities. First, sometimes we explain what made sense to an agent by appealing to an entire worldview, a general way of conceiving things. It is hard to explain why suicide would seem the only honorable response to career failure to an ancient patrician Roman without appealing to moral assumptions that might have passed unnoticed in Roman times, but which come to light when we contrast them with our own moral assumptions. These assumptions may figure mentally not as content-bearing elements of one's belief box but in individuals' patterns of thought, motivation, and intention. However, these assumptions or patterns of response only instrumentally explain the intelligibility of suicide. They explain it by explaining why the Roman in dire straits would come to see suicide as honorable. This conscious recognition, in turn, would non-instrumentally explain the intelligibility of suicide.

The second possibility is to hold that while completely unconscious motivations do not make actions intelligible, except perhaps instrumentally, consciously accessible motivations do. After all, in executing a prior intention to $\phi$ we need not consciously rehearse our reasons for $\phi$ ing. When the time comes, we simply $\phi$. Still we retain our reasons for $\phi$ ing, and so $\phi$ ing must be intelligible to us.

But if this is right, it does not show that the intelligibility of $\phi$ ing is not to be explained in terms of the content of a state. What enables $\phi$ ing in this case to be done for a reason is that one's reasons for $\phi$ ing are consciously accessible, either through being actually conscious, or being available to consciousness through attention or recall. After all, if one $\phi s$ for a reason in the full-blooded sense at issue in this paper, then one must have an answer to the question, "Why [did you do that]?" which gives one's reasons for acting, and it seems the only way one has such an answer is if one's reasons for acting are consciously accessible. Now, according to GG, motivation makes action intelligible by making it appear good in some respect. If it does so in virtue of the content of some state of appearing good when that state is conscious, then it seems that, if action can also be intelligible in virtue of such a state being consciously accessible but not accessed, then it is still the goodness-bearing content of that state that enables its contribution to action's intelligibility. For mental states do not massively change their content just for being consciously accessed.

In other words, the attitudinal theorist may complain that the sense in which GG requires mental access to the good requires only that the good of one's action be consciously accessible, not that it be actually accessed. But amending prem- 
ise 2 to reflect this possibility would not help her, for what is at issue is only the accessibility of a state with goodness-bearing content. When an action is intelligible to an agent, it is still in virtue of the content of some of their mental states, contrary to what the attitudinal model holds.

\section{CONCLUSION}

The intelligibility constraint provides an attractive motivation for the Guise of the Good. Warren Quinn pointed out that without seeing something good about acting, action is not intelligible. It "fails for want of a point"-fails, that is, to have a reason that rationalizes it. ${ }^{73} \mathrm{GG}$ theorists are inclined to agree. But an important class of GG theorists, the attitudinalists, are unable to keep up with the commitments that ultimately derive from this basic insight. In order to reply to Setiya's objection from apparent thin goods, these theorists need to appeal to a specific kind of good that makes action intelligible. But this leaves them with a dilemma: either they characterize the connection to the specific evaluative property in a way that makes an assertoric view far more plausible, or they fail to explain the agent's mental access to the good, as GG requires. ${ }^{74}$

Centre de recherche en éthique

Université de Montréal paul.s.boswell@gmail.com

\section{REFERENCES}

Anscombe, G. E. M. Intention. 2nd ed. Oxford: Blackwell, 1963.

Baker, Derek. "The Abductive Case for Humeanism over Quasi-Perceptual Theories of Desire." Journal of Ethics and Social Philosophy 8, no. 2 (October 2014): 1-29.

Bermúdez, José Luis. “The Distinction between Conceptual and Nonconceptual Content." In The Oxford Handbook of Philosophy of Mind, edited by Ansgar Beckermann, Brian P. McLaughlin, and Sven Walter, 457-73. New York: Oxford University Press, 2009.

73 Quinn, "Putting Rationality in Its Place," 34.

74 Thanks to Samuel Asarnow, Daniel Drucker, Mauro Rossi, Christine Tappolet, Valéry Giroux, Kieran Setiya, Uriah Kriegel, Nandi Theunissen, Jens Gillessen, Angie Pepper, Sarah Buss, Stephen White, two referees at the Journal of Ethics and Social Philosophy, and audiences in Paris, Montreal, and Evanston for comments that greatly improved the paper. 
Boswell, Paul. "Affect, Representation, and the Standards of Practical Reason." $\mathrm{PhD}$ diss., University of Michigan, 2016.

Boyle, Matthew, and Douglas Lavin. "Goodness and Desire." In Tenenbaum, Desire, Practical Reason, and the Good, 161-201.

Brentano, Franz. Psychology from an Empirical Standpoint. 1874. Edited by Oskar Kraus and Linda L. McAlister. Translated by Antos C. Rancurello, D. B. Terrell, and Linda L. McAlister. London: Routledge, 1995.

Brewer, Talbot. “Three Dogmas of Desire." In Values and Virtues: Aristotelianism in Contemporary Ethics, edited by Timothy Chappell, 257-84. Oxford: Oxford University Press, 2006.

Buss, Sarah. "What Practical Reasoning Must Be If We Act for Our Own Reasons." Australasian Journal of Philosophy 77, no. 4 (December 1999): 399-421. Chisholm, Roderick M. Perceiving: A Philosophical Study. Ithaca, NY: Cornell University Press, 1957.

Clark, Philip. "Aspects, Guises, Species, and Knowing Something to Be Good." In Tenenbaum, Desire, Practical Reason, and the Good, 234-44.

Davidson, Donald. "Actions, Reasons, and Causes." In Essays on Actions and Events, 3-20.

- Essays on Actions and Events. 2nd ed. Oxford: Oxford University Press, 2001.

. "How Is Weakness of the Will Possible?" In Essays on Action and Events, $21-42$.

- "Intending." In Essays on Actions and Events, 83-102.

Deonna, Julien A., and Fabrice Teroni. The Emotions: A Philosophical Introduction. London: Routledge, 2012.

Dokic, Jérôme, and Stéphane Lemaire. "Are Emotions Evaluative Modes?" Dialectica 69, no. 3 (September 2015): 271-92.

Ducasse, C.J. "Moore's Refutation of Idealism." In The Philosophy of G. E. Moore, edited by Paul A. Schilpp, 223-53. La Salle, IL: Open Court, 1942.

Fodor, Jerry A. "Propositional Attitudes." The Monist 61 (October 1978): 501-23. Glass, Ira. "Devil on My Shoulder." This American Life. Podcast audio, May 24, 2002. http://thisamericanlife.org/radio-archives/episode/213/transcript.

Gregory, Alex. "The Guise of Reasons." American Philosophical Quarterly 50, no. 1 (January 2013): 63-72.

Hawkins, Jennifer. "Desiring the Bad under the Guise of the Good." The Philosophical Quarterly 58, no. 231 (April 2008): 244-64.

Jackson, Frank. Perception: A Representative Theory. Cambridge: Cambridge University Press, 1977. 
Johnston, Mark. "The Authority of Affect." Philosophy and Phenomenological Research 63, no. 1 (July 2001): 181-214.

Korsgaard, Christine M. Self-Constitution: Agency, Identity, and Integrity. New York: Oxford University Press, 2009.

Kriegel, Uriah. Brentano's Philosophical System: Mind, Being, Value. Oxford: Oxford University Press, forthcoming.

. "The Dispensability of (Merely) Intentional Objects." Philosophical Studies 141, no. 1 (October 2008): 79-95.

MacIntyre, Alasdair. "The Intelligibility of Action." In Rationality, Relativism, and the Human Sciences, edited by Michael Krausz, Richard M. Burian, and Joseph Margolis, 63-8o. Dordrecht: M. Nijhoff, 1986.

Martin, Michael G. F. "Setting Things before the Mind." In Contemporary Issues in the Philosophy of Mind, edited by Anthony O'Hear, 157-80. Cambridge: Cambridge University Press, 1998.

Massin, Olivier. "Desires, Values and Norms." In The Nature of Desire, edited by Federico Lauria and Julien Deonna, 165-200. Oxford: Oxford University Press, 2017.

Nisbett, Richard E., and Timothy D. Wilson. "Telling More Than We Can Know: Verbal Reports on Mental Processes." Psychological Review 84, no. 3 (May 1977): 231-59.

Nussbaum, Martha. Upheavals of Thought: The Intelligence of Emotions. Cambridge: Cambridge University Press, 2001.

Oddie, Graham. Value, Reality, and Desire. Oxford: Oxford University Press, 2005.

Orsi, Francesco. "The Guise of the Good." Philosophy Compass 10, no. 10 (October 2015): 714-24.

Quinn, Warren S. "Putting Rationality in Its Place." In Value, Welfare, and Morality, edited by Christopher W. Morris and R. G. Frey, 26-49. Cambridge: Cambridge University Press, 1993.

Raz, Joseph. "Agency, Reason, and the Good." In Engaging Reason, 22-45.

- Engaging Reason: On the Theory of Value and Action. New York: Oxford University Press, 1999.

- "The Guise of the Bad." Journal of Ethics and Social Philosophy 10, no. 3 (July 2016): 1-14.

- "Incommensurability and Agency." In Incommensurability, Incomparability, and Practical Reason, edited by Ruth Chang, 110-28. Cambridge, MA: Harvard University Press, 1997.

- "On the Guise of the Good." In Tenenbaum, Desire, Practical Reason, and the Good, 111-37. 
_ . "Reason, Rationality, and Normativity." In From Normativity to Responsibility, 85-101. Oxford: Oxford University Press, 2011.

- "Reasons: Explanatory and Normative." In New Essays on the Explanation of Action, edited by Constantine Sandis, 184-202. New York: Palgrave Macmillan, 2009.

_. "When We Are Ourselves: The Active and the Passive." In Engaging Reason, 5-22.

Saemi, Amir. "Aiming at the Good." Canadian Journal of Philosophy 45, no. 2 (2015): 197-219.

- "The Guise of the Good and the Problem of Over-Intellectualism." Journal of Value Inquiry 48, no. 3 (September 2014): 489-501.

Scanlon, Thomas M. What We Owe to Each Other. Cambridge, MA: Harvard University Press, 1998.

Schafer, Karl. "Perception and the Rational Force of Desire." Journal of Philosophy 110, no. 5 (May 2013): 258-81.

Schapiro, Tamar. “The Nature of Inclination.” Ethics 119, no. 2 (January 2009): 229-56.

- "What Are Theories of Desire Theories Of?" Analytic Philosophy 55, no. 2 (June 2009): 131-50.

Schroeder, Mark. "How Does the Good Appear to Us?" Social Theory and Practice 34, no. 1 (January 2008): 119-30.

Setiya, Kieran. Reasons without Rationalism. Princeton: Princeton University Press, 2007.

- "Sympathy for the Devil." In Tenenbaum, Desire, Practical Reason, and the Good, 82-110.

Silverstein, Matthew. "Agency and Normative Self-Governance." Australasian Journal of Philosophy 95, no. 3 (2016): 517-28.

Smith, Michael. "A Constitutivist Theory of Reasons: Its Promise and Parts." Law, Ethics and Philosophy 1 (2013): 9-30.

Solomon, Robert C. "Emotions and Choice." Review of Metaphysics 27, no. 1 (September 1973): 20-41.

Stampe, Dennis W. "The Authority of Desire." Philosophical Review 96, no. 3 (July 1987): 335-81.

Stocker, Michael. "Desiring the Bad." Journal of Philosophy 76, no. 2 (December 1979): $738-53$.

_ . "Raz on the Intelligibility of Bad Acts." In Reason and Value: Themes from the Moral Philosophy of Joseph Raz, edited by R. Jay Wallace, Philip Pettit, Samuel Scheffler, and Michael Smith, 303-32. New York: Oxford University Press, 2004. 
Sussman, David. “For Badness' Sake." Journal of Philosophy 106, no. 11 (November 2009): 613-28.

Tappolet, Christine. Emotions, Values, and Agency. Oxford: Oxford University Press, 2016.

Tenenbaum, Sergio. Appearances of the Good. Cambridge: Cambridge University Press, 2007.

. "Appearing Good: A Reply to Schroeder." Social Theory and Practice 34, no. 1 (January 2008): 131-38.

- ed. Desire, Practical Reason, and the Good. New York: Oxford University Press, 2010.

- "Guise of the Good." In The International Encyclopedia of Ethics, edited by Hugh LaFollette, 2262-71. Hoboken, NJ: Wiley, 2013.

Velleman, J. David. "The Guise of the Good." In The Possibility of Practical Reason, 99-122.

- "Introduction." In The Possibility of Practical Reason, 1-31.

. The Possibility of Practical Reason. Oxford: Oxford University Press, New York, 2000.

- "The Possibility of Practical Reason." In The Possibility of Practical Reason, $170-99$.

Vogler, Candace. Reasonably Vicious. Cambridge, MA: Harvard University Press, 2002.

Wiland, Eric. Reasons. London: Continuum, 2012. 